\title{
Sporcularda Kronik Dental Lezyonların Kas Kuvvetine Etkisi
}

\section{The Effect of Chronic Dental Lesions on Muscle Strength in Athletes}

\author{
Tuğba KOCAHAN ${ }^{1}$, Osman HAMAMCILAR ${ }^{1}$, Aydın BALCI ${ }^{1,2}$, Bihter AKINOĞLU ${ }^{1,3}$, \\ Nevres Hürriyet AYDOĞAN ${ }^{4}$, Adnan HASANOĞLU ${ }^{1}$ \\ ${ }^{1}$ Gençlik ve Spor Bakanlığı, Sporcu Eğitim, Sağlık ve Araştırma Merkezi (SESAM), Ankara \\ ${ }^{2}$ Ankara Yıldırım Beyazıt Üniversitesi, Yenimahalle Eğitim ve Araştırma Hastanesi, Spor Hekimliği, Ankara \\ ${ }^{3}$ Ankara Yıldırım Beyazıt Üniversitesi, Sağlık Bilimleri Fakültesi, Fizyoterapi ve Rehabilitasyon Bölümü, Ankara \\ ${ }^{4}$ Muğla Sitkı Koçman Üniversitesi, Tıp Fakültesi, Ortopedi ve Travmatoloji Anabilim Dalı, Muğla
}

\begin{abstract}
$\overline{\mathbf{O z}}$
Sporcularda diș çürükleri, diș erozyonları, periodontal hastalıklar, oklüzyon bozuklukları, temporomandibular eklem bozuklukları ve orofasial yaralanmalar gibi kronik dental lezyonların yaygın görüldüğü ve bu durumun hem genel sağlığı hem de spor performansını olumsuz etkilediği bildirilmektedir. Çalışmamızın amacı ağız içinde kronik dental lezyonlardan periapikal lezyonu olan ve olmayan sporcularda diz eklemi izokinetik kas kuvvetini karşılaştırmaktır. Çalışmaya periapikal lezyonu olan $(n=16$; çalışma grubu) ve aynı spor branşında, aynı cinsiyette ve benzer demografik özelliklere sahip ve periapikal lezyonu olmayan (n=16; kontrol grubu) toplam 32 sporcu dâhil edildi. Tüm sporcular aynı diş hekimi tarafindan tek kullanımlık muayene seti ile muayene edildi ve panoramik radyografi ile değerlendirildi. Muayene ve radyolojik değerlendirme sonrası periapikal lezyonu olan sporcular çalışma grubu olarak; periapikal lezyonu olmayan sporcular kontrol grubu olarak belirlendi. Daha sonra sporcuların diz eklemi fleksör ve ekstansör kaslarının kas kuvveti IsoMed 2000 izokinetik dinamometre ile konsantrik olarak değerlendirildi. Çalışmada ve kontrol grubunun izokinetik kas kuvveti karşılaştırmaları dağılım durumuna göre Independent Samples $\mathrm{T}$ test ve Mann Whitney-U testi ile analiz edildi. Anlamlılık düzeyi $p<0.05$ olarak alındı. Çalışma ve kontrol grubu sporcularının $60^{\circ}$ sn ve $180^{\circ} / \mathrm{sn}$ açısal hızlarda diz eklemi fleksör ve ekstansör kaslarının konsantrik izokinetik kas kuvvetinin benzer olduğu belirlendi $(p>0.05)$. Ağız içinde periapikal lezyonu olan ve olmayan sporcuların diz eklemi konsantrik izokinetik kas kuvvetinin olumsuz etkilenmediğini söyleyebiliriz.

Anahtar Kelimeler: Diş, İzokinetik, Performans, Periapikal Lezyonlar, Spor

Abstract

It has been reported that chronic dental lesions such as dental caries, tooth erosions, periodontal diseases, occlusion disorders, temporomandibular joint disorders, and orofacial injuries are common in athletes and this situation negatively affects both general health and sports performance. Our study aims to compare the isokinetic muscle strength of the knee joint in athletes with and without periapical lesions which are chronic dental lesions in the mouth. 32 athletes with periapical lesions ( $\mathrm{n}=16$; study group), same gender, similar demographic characteristics, and no periapical lesions( $\mathrm{n}=16$; control group) were included in the study. All athletes were examined by the same dentist using a disposable examination set and evaluated with panoramic radiography. Athletes with periapical lesions after examination and radiological evaluation as the study group; athletes without periapical lesions were determined as the control group. Then, the muscle strength of the knee joint flexor and extensor muscles of the athletes was evaluated concentrically with the IsoMed 2000 isokinetic dynamometer. Isokinetic muscle strength comparisons of the study and control groups were analyzed according to the distribution status by Independent Samples T-test, Mann Whitney-U test. The level of significance was taken as $\mathrm{p}<0.05$. Concentric isokinetic muscle strengths of knee joint flexor and extensor muscles were found to be similar at $60 \% \mathrm{sec}$ and $180^{\circ} / \mathrm{sec}$ angular velocities of study and control group athletes $(p>0.05)$. We can say that the concentric isokinetic muscle strength of the knee joint of athletes with periapical lesions in the mouth and without periapical lesions was not affected negatively.

Keywords: Tooth, Isokinetic, Performance, Periapical lesions, Sports
\end{abstract}

\section{Giriş}

Kötü ağız hijyenine bağlı gelişen çürük dişler ve periodontal hastalıklar ağız boşluğunun en sık görülen bakteriyel hastalıklarıdır. Tedavi edilmeyen çürükler pulpanın nekrozuna ve apikal periodontitisin başlamasına ve enfeksiyonun periapikal kistler, granülomlar veya apseler şeklinde ilerlemesine neden olur. $\mathrm{Bu}$ periodontal fokal enfeksiyon odakları kardiyovasküler hastalıklar,

\begin{tabular}{|c|c|}
\hline & ORCID No \\
\hline Tuğba KOCAHAN & 0000-0002-0567-857X \\
\hline Osman HAMAMCILAR & $0000-0002-1589-871 X$ \\
\hline Aydın BALCI & 0000-0002-9072-3397 \\
\hline Bihter AKINOĞLU & 0000-0002-8214-7895 \\
\hline Nevres Hürriyet AYDOĞAN & $0000-0002-1837-2676$ \\
\hline Adnan HASANOĞLU & 0000-0003-4486-5092 \\
\hline Başvuru Tarihi / Received: & 15.03.2021 \\
\hline Kabul Tarihi / Accepted : & 25.08 .2021 \\
\hline Adres / Correspondence : & Tuğba KOCAHAN \\
\hline $\begin{array}{l}\text { Sağlık Bilimleri Üniversitesi, } \\
\text { Hekimliği AD, Ankara }\end{array}$ & Gülhane Tip Fakültesi, Spor \\
\hline e-posta / e-mail & kocahantu@gmail.com \\
\hline
\end{tabular}

solunum sistemi hastalıkları, diyabet, artrit, erken doğum ve alopesi areata gibi sistemik hastalıklar için risk faktörüdür (1-7).

Sporcularda kötü ağız sağlığı ve travmaya bağl1 olarak diş çürükleri, diş erozyonları, periodontal hastalıklar, oklüzyon bozuklukları, temporomandibular eklem bozuklukları ve orofasial yaralanmalar gibi kronik dental lezyonlar yaygın görülür ve bu durum hem genel sağlığ 1 hem de spor performansinı olumsuz etkiler (3,8-16). Sporculardaki kötü ağız sağlığına karbonhidrat ve protein içeriği yüksek beslenme alışkanlıkları, dehidratasyon, kuru ağız (azalmış tükürük salgısı), yeme bozukluğu, antrenman dönemlerinde şeker ve asit oranı yüksek içeceklerin tüketilmesi, stres düzeyleri, bireysel diş firçalama sıklığının iyi olmaması gibi birçok faktör neden olmaktadır $(8,13,17,18)$. Ağız içinde kronik enflamasyona neden olan lezyonlar; kronikleşen tendinitis, pubalji, hamstring lezyonu veya patellofemoral sendrom gibi spor yaralanmaları için risk teşkil eden fokal enfeksiyon odaklarıdır $(9,18)$. Futbolcular üzerinde yapılan bazı çalışmalarda yoğun tıbbi tedavi ve 
takibe rağmen çürükler, diş eti iltihabı veya maloklüzyon gibi önemli ağız sağlığı sorunlarının yaşandığı, spor aktivitelerine bağlı diş travmalarının görüldüğü ve kas yaralanmaları ile ağız sağlığı arasında bir korelasyon olduğu bildirilmiștir $(9,14)$. Aynı zamanda stomatognatik sistem ile kas iskelet sistemi arasında bir etkileşim olduğu ve spor performansını olumsuz etkileyebileceği bildirilmektedir $(11,15,19)$.

Londra 2012 Yaz Olimpiyat Oyunlarına katılan sporcular üzerinde yapılan bir çalışmada diş çürükleri $(\% 55)$, diş erozyonu $(\% 45)$ ve periodontal hastalık (gingivitis \%76, periodontitis \%15) olmak üzere yüksek düzeyde kötü ağız sağlığı tespit edilmiştir. Sporcuların \%40'1 ağız sağlığından rahatsız olduğunu, $\% 28$ 'i yaşam kalitesi ve \%18'i antrenman ve performans üzerinde olumsuz bir etkisi olduğunu bildirmiştir (16).

Sporcularda yaygın görülen kötü ağız sağlığının neden olduğu kronik dental lezyonlar, ağız içinde fokal enfeksiyon odakları oluşturur ve genel sağlık durumu, antrenman ve spor performansı üzerine olumsuz etkiler gösterir $(16,20)$. $\mathrm{Bu}$ bilgilerden yola çıkarak bu çalışmadaki amacımız ağız içinde kronik dental lezyonlardan periapikal lezyonu olan ve olmayan sporcularda diz eklemi izokinetik kas kuvvetini karşılaştırmaktır.

\section{Gereç ve Yöntem}

Çalışma Gençlik ve Spor Bakanlığı, Sporcu Eğitim Sağlık ve Araştırma Merkezi (SESAM)'da yapıldı. Çalışmaya katılan sporculara testler hakkında gerekli bilgilendirmeler yapıldı ve onam formu imzalatıldı. Çalışma, 2008 Helsinki Deklarasyon Prensipleri'ne uygun olarak yapıldı ve çalışmanın yapılabilmesi için Ankara Yıldırım Beyazıt Üniversitesi Sosyal ve Beşeri Bilimler Etik Kurulundan onay alındı (2020-358/08).

Sporcular, uygulanacak testlere uygunluk açısından ilk önce spor hekimliği uzmanı tarafından muayene edilerek sorgulandı, ardından doğum tarihleri, boy uzunluğu ve vücut ağırlığı gibi demografik bilgileri alındı. Daha sonra sporcuların ağız ve diş muayenesi aynı diş hekimi tarafından yapıldı. Ardından diz eklemi fleksör ve ekstansör kaslarının kas kuvveti IsoMed 2000 izokinetik dinamometre ile konsantrik olarak alanında en az 3 yıl deneyimli aynı fizyoterapist tarafından değerlendirildi.

Sporcuların çalışmaya alınma kriterleri; bilinen herhangi bir sistemik hastalığ lisanslı sporcu olmak, çalışmada uygulanacak parametrelere koopere olmak, uygulanacak testleri yapabiliyor olmak ve çalışmaya katılmaya gönüllü olmak olarak belirlendi. Sporcuların çalışmaya dâhil edilmeme kriterleri: hâlihazırda akut ya da kronik spor yaralanmasına sahip olmak, alt ekstremite ile ilgili herhangi bir cerrahi operasyon geçirmiş olmak, sol taraf dominant olmak olarak belirlendi.

Çalışmaya kriterlere uyan ve periapikal lezyonu olan ( $\mathrm{n}=16$; çalışma grubu) ve aynı spor branşında, aynı cinsiyette ve benzer demografik özelliklere sahip ve periapikal lezyonu olmayan $(\mathrm{n}=16$; kontrol grubu) toplam 32 sporcu dâhil edildi.

Ağız ve Diş Sağlığı Muayenesi: Sporcular aynı diş hekimi tarafından tek kullanımlık ağız içi muayene seti ile muayene edildi ve son üç gün içinde çekilmiş panoramik radyografisi değerlendirildi. Muayene ve panoramik radyografi değerlendirmesi sonucunda periapikal lezyon tespit edilen sporcular çalışma grubu olarak; herhangi bir periapikal lezyon, diş ve dişeti hastalığı tespit edilmeyen sporcular kontrol grubu olarak belirlendi.

İzokinetik Kas Kuvvetinin Değerlendirilmesi: İzokinetik kas kuvveti IsoMed 2000 (D.\& R. Ferstl $\mathrm{GmbH}$, Hemau, Almanya) izokinetik dinamometre ile değerlendirildi. Teste başlamadan önce sporcuların 1sınma egzersizi olarak $10 \mathrm{dk}$ boyunca resiprokal bisiklet ergometresi ile dakikada 60 devir sayısı ile ısınmaları sağlandı. Testler oturma pozisyonunda uyguland1. Sporcular, cihazın omuz aparatı ile omuzlar üzerinden, stabilizasyon bantları ile bel ve distal femur üzerinden stabilize edildi. Pivot nokta femurun lateral kondili olacak şekilde ayarlandı. Testler sırasında sporculara sözlü olarak cesaret verildi. Diz fleksör ve ekstansör kaslarının kuvveti $60 \%$ sn ve $180^{\circ}$ sn açısal hızlarda konsantrik olacak şekilde değerlendirildi. Değerlendirmede her hareket ve hızdan önce üç tekrarlı ısınma ve hareketi anlama egzersizi yaptırıldı. Değerlendirme sonucunda; diz ekstansör kasları için $60 \%$ sn ve $180^{\circ}$ sn hizlarda ayrı ayrı zirve kuvvet [peak torque $(\mathrm{PT})]$ ve rölatif zirve kuvvet $(\mathrm{PT} / \mathrm{kg})$ değerleri kaydedildi (21).

İstatistiksel Analiz; Çalışmanın istatistikleri SPSS 20.0 programı kullanılarak yapıldı. Değişkenlerin normal dağılıma uygunluğu Shapiro-Wilk testi ile belirlendi. Çalışma ve kontrol grubunun ağız ve diş sağlığı muayenesi ve kas kuvvet ölçümü sonucu uygunluk düzeyine göre bağımsız gruplar t testi ve Mann Whitney-U testi ile değerlendirildi. Değişkenler ortalama \pm standart sapma $\left(\mathrm{X}^{-} \pm \mathrm{SS}\right)$ ve ortanca (birinci ve üçüncü çeyreklik) ile gösterildi. İstatistiksel hata düzeyi $\mathrm{p}<0.05$ olarak belirlendi.

\section{Bulgular}

Çalışma ve kontrol grubu sporcularının yaş, vücut ağırlığı, boy uzunluğu, beden kütle indeksi ve spor yılı bakımından benzer olduğu belirlendi $(\mathrm{p}>0.05)$ (Tablo 1). Ağız ve diş muayenesi sonucu belirlenen çekilmiş diş ve dolgulu diş sayısı bakımından gruplar arasında istatistiksel olarak anlamlı fark olduğu ve çalışma grubunda çekilmiş diş ve dolgulu diş sayısının daha fazla olduğu belirlendi $(\mathrm{p}<0.05)$. Ağız ve diş muayenesi sonucu belirlenen çürük diş sayısı ve periodontal doku hastalığ 1 bakımından gruplar arasında istatistiksel olarak anlamlı fark olmadığı belirlendi $(\mathrm{p}>0.05)$ (Tablo 1).

Çalışma ve kontrol grubu sporcularının $60^{\circ} / \mathrm{sn}$ ve $180^{\circ}$ sn açısal hızlarda dominant ve non-dominant taraf diz eklemi fleksör ve ekstansör kaslarının konsantrik izokinetik kas kuvveti arasında istatistiksel olarak anlamlı fark olmadığı belirlendi ( $\mathrm{p}>0.05$ ) (Tablo 2). 
Tablo 1. Sporcuların demografik özellikleri ve ağız ve diş sağlığı muayenesi sonuçları ve karşılaştırılması

\begin{tabular}{lccc}
\hline & Kontrol Grubu n=16 & Çalışma Grubu n=16 & $\mathrm{p}$ \\
\hline Yaş (yıl) & $17.38 \pm 1.59$ & $17.38 \pm 1.59$ & 1.000 \\
Vücut Ağırlı̆̆ı (kg) & $60.32 \pm 7.75$ & $63.32 \pm 8.60$ & 0.308 \\
Boy Uzunluğu (m) & $1.69 \pm 0.10$ & $1.71 \pm 0.07$ & 0.519 \\
Beden Kütle İndeksi (kg/m²) & $21.18 \pm 1.41$ & $21.74 \pm 2.42$ & 0.428 \\
Spor Yılı (yıl) & $7(5-7.5)$ & $6.5(5-9.5)$ & 0.926 \\
Çürük Diş Sayısı (adet) & 0 & $1(0-2)$ & 0.539 \\
Çekilmiş Diş Sayısı (adet) & 0 & $0(0-2)$ & 0.008 \\
Dolgulu Diş Sayısı (adet) & 0 & $1(0-5)$ & 0.002 \\
Periodontal Hastalık Varlığı (var/yok) & 0 & $16 / 3(\% 19)$ & \\
\hline
\end{tabular}

Tablo 2. Çalışma ve kontrol grubu sporcularının izokinetik kas kuvvetinin karşılaştırılması

\begin{tabular}{|c|c|c|c|c|c|}
\hline & & & Kontrol Grubu n=16 & Çalışma Grubu n=16 & $\mathrm{p}$ \\
\hline \multirow{8}{*}{ 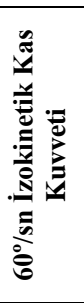 } & \multirow{4}{*}{ Fleksiyon } & Dominant PT (N) & $109.05 \pm 27.19$ & $105.23 \pm 21.49$ & 0.663 \\
\hline & & Dominant PT/W (N/kg) & $1.77(1.51-2.08)$ & $1.67(1.51-1.88)$ & 0.160 \\
\hline & & Non-Dominant PT (N) & $103.14 \pm 25.26$ & $103.18 \pm 23.14$ & 0.997 \\
\hline & & Non-Dominant PT/W (N/kg) & $1.71 \pm 0.30$ & $1.57 \pm 0.39$ & 0.275 \\
\hline & \multirow{4}{*}{ Ekstansiyon } & Dominant PT (N) & $204.30 \pm 46.87$ & $199.75 \pm 46.32$ & 0.784 \\
\hline & & Dominant PT/W (N/kg) & $3.38(3.08-3.86)$ & $3.19(2.76-3.51)$ & 0.254 \\
\hline & & Non-Dominant PT (N) & $195.31 \pm 44.72$ & $190.33 \pm 55.07$ & 0.781 \\
\hline & & Non-Dominant PT/W (N/kg) & $3.25 \pm 0.57$ & $2.89 \pm 0.84$ & 0.168 \\
\hline \multirow{8}{*}{ 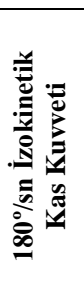 } & \multirow{4}{*}{ Fleksiyon } & Dominant PT (N) & $89.86 \pm 21.67$ & $84.78 \pm 15.33$ & 0.450 \\
\hline & & Dominant PT/W (N/kg) & $1.51(1.36-1.65)$ & $1.37(1.27-1.46)$ & 0.051 \\
\hline & & Non-Dominant PT (N) & $119.31 \pm 48.14$ & $116.55 \pm 48.66$ & 0.873 \\
\hline & & Non-Dominant PT/W (N/kg) & $1.95 \pm 0.66$ & $1.79 \pm 0.79$ & 0.538 \\
\hline & \multirow{4}{*}{ Ekstansiyon } & Dominant PT (N) & $148.54 \pm 31.81$ & $144.30 \pm 32.84$ & 0.713 \\
\hline & & Dominant PT/W (N/kg) & $2.53(2.19-2.69)$ & $2.33(2.09-2.43)$ & 0.171 \\
\hline & & Non-Dominant PT (N) & $143.17 \pm 31.91$ & $141.59 \pm 34.88$ & 0894 \\
\hline & & Non-Dominant PT/W (N/kg) & $2.33(2.17-2.66)$ & $2.25(2.04-2.36)$ & 0.184 \\
\hline
\end{tabular}

\section{Tartışma}

Sporcularda diş çürükleri, diş erozyonları, periodontal hastalıklar, oklüzyon bozuklukları, temporomandibular eklem bozuklukları ve orofasial yaralanmalar gibi kronik dental lezyonların yaygın görüldüğü ve bu durumun hem genel sağlığı hem de spor performansını olumsuz etkilediği bildirilmektedir (3,8-16). Ağız içinde kronik dental lezyonlardan periapikal lezyonu olan ve olmayan sporcularda diz eklemi izokinetik kas kuvvetini karşılaştırmak amacıyla gerçekleştirdiğimiz çalışmamız sonucunda ağız içi periapikal lezyonu olan ve olmayan sporcuların diz eklemi konsantrik izokinetik kas kuvvetinin benzer olduğu belirlendi.

Sporcularda spora bağlı yeme alışkanlıkları, karbonhidrat ve protein içeriği yüksek beslenme, antrenman sırasında şeker ve asit içeriği yüksek gıdaların ve sıvıların tüketimi, tükürük salınımındaki azalma, ağız kuruluğu ve orofasial travmalara maruz kalınması ağız içi lezyonların yaygın görülmesine neden olmaktadır $(8,11-13,17,18,22)$. Sporcularda diş çürükleri, dişlerde erozyonlar ve buna bağlı gelişen periapikal lezyonlar ve periodontal hastalıklar ağız içinde fokal enfeksiyon odaklarının oluşmasına neden olur. Bu odaklardan sistemik dolaşıma katılan patojen mikroorganizmaların ve mediatörlerin ise sistemik hastalıklara, disbiyozise ve sporcularda 1srarlı tendinopati ve kas iyileşmesinde gecikmelere neden olabildiği bildirilmektedir $(9,14,16,18,20)$. Benzer şekilde kötü ağız sağlığının sporcularda genel iyilik hali, antrenman ve spor performansinı bozduğu bildirilmektedir $(16,20)$. Ancak literatürde sporcularda ağız ve diş sağlığı ile spor performansı arasındaki ilişkiyi ve ağız diş sağlığının performansa etkisini inceleyen çalışma sayısı sınırlıdır. Bu bilgiler 1şı̆̆ında klinik ve radyografik olarak periapikal lezyon tespit edilen sporcularda ve periapikal lezyon tespit edilmeyen sporcularda performansın önemli bir bileşeni olan kas kuvvetini değerlendirmeyi amaçladık. Yaptığımız değerlendirmede periapikal lezyonu olan sporcularda kontrol grubuna göre kas kuvvetinde anlamlı bir fark görülmedi. Literatürde ağız ve diş sağlığının kas kuvvetine etkisini inceleyen çalışma sayısı çok azdır. Dört sporcu ile yapılan bir vaka çalışmasında diş çekimi sonrası diz eklemi izokinetik kas kuvveti ve performansının azaldığ 1 belirtilirken (19), çalışmamızın sonuçlarına paralel olarak başka bir çalışmada mine-dentin seviyesindeki diş çürükleri ile dizin fleksör ve ekstansör kas kuvveti arasında çok düşük seviyede negatif yönde bir korelasyon olduğu, ancak bunun istatistiksel olarak anlamlı olmadığı bildirilmiştir (23).

Kötü ağı sağlığının spor performansına etkisinin incelendiği diğer çalışmalara baktığımızda 
mine ve dentin seviyesindeki yüzeysel diş çürüklerinin sporcuların anaerobik performansına olumsuz bir etkisinin olmadiğ fonksiyonları üzerindeki etkisinin incelendiği bir çalışmada ise yüksek çürük skorunun, DMF-T indeks değerinin ve periodontal hastalıkların FEV1/FVC\% de azalmaya neden olduğu, dolayısıyla solunum fonksiyonlarını ve spor performansını olumsuz etkilediği bildirilmiştir (25).

Çalışmamıza aynı spor branşı, aynı cinsiyet ve aynı demografik özelliklere sahip sporcuların dahil edilmiş olması, ağız ve diş sağlığının klinik ve radyolojik olarak değerlendirilmiş olması ve performansın en önemli bileşenlerinden biri olan kas kuvvetinin alanında altın standart olarak kabul edilen izokinetik dinamometre (26) ile değerlendirilmiş olması çalışmayı güçlü kılmaktadır. Bununla birlikte aerobik ve anaerobik kapasite ve etkilenmesi muhtemel diğer bir parametre olan solunum fonksiyonları gibi performansın diğer bileşenlerinin değerlendirilmemiş olması çalışmamızın kısıtlılıklarıdır. Ayrıca yapılan bir çalışmada periapikal lezyon tespit edilen hastaların klinik, radyografik ve histolojik bulguları karşılaştırılmış, klinik ve radyografik olarak kronik apikal periodontitis olduğu doğrulanmıș vakaların $\% 36$ ' 1 ve yine klinik ve radyografik olarak enflamatuar apikal kist olduğu doğrulanmış vakaların \%36's1 histolojik olarak tanıy doğrulamamıştır. Yani klinik, radyolojik ve histolojik tanıda bir uyumsuzluk söz konusudur (27). Aynı zamanda periapikal lezyonlar gibi ağız içinde kronik enflamasyon yaratan patolojiler kanda serum reaktif protein (CRP) ve sitokinlerde artışa neden olmaktadır. $\mathrm{Bu}$ durum egzersiz esnasında kas yorgunluğu ve aerobik performansın azalmasında ve egzersiz sonrası oksidatif stres gelişiminde önemli rol oynar (28-30). Çalışmamızdaki tüm vakaların klinik ve radyolojik olarak değerlendirilmiş ancak histolojik olarak periapikal lezyonların doğrulanmamış olması ve kanda enflamasyon mediatörlerinin çalışılmamış olması da diğer kısıtlılıklar olarak görülebilir. Ağız içi patolojilerin klinik, radyolojik ve histolojik olarak doğrulandığ1 ve enflamasyon mediatörlerinin de değerlendirildiği geniş katılımlı sporcu gruplarında kötü ağız sağlığının spor performansına etkisinin incelendiği çalışmalara ihtiyaç olduğunu düşünmekteyiz.

Sonuç olarak, bu çalışma ile ağız sağlığı, kronik dental lezyonlar ve bu lezyonlardan biri olan periapikal lezyonlar, diz eklemi kas kuvvetinde anlamlı bir farklılığa neden olmasa da sporcularda ağız diş sağlığı dikkate alınmalıdır. Periapikal lezyonların hiç semptom vermeden ilerleyebildiği unutulmamalıdır. Ağız ve diş sağlığı genel sağlığın ayrılmaz bir parçasıdır. Sporcularda kötü ağız sağlığ1 ve buna bağlı ağı içi patolojiler yaygın görüldügünden sporcuların periyodik olarak ağız ve diş sağlığı muayenelerini yaptırmaları gerektiğini düşünmekteyiz.
Etik Kurul Onayı: Ankara Yıldırım Beyazıt Üniversitesi Sosyal ve Beşeri Bilimler Etik Kurulundan onay alınmıştır (2020-358/08).

\section{Kaynaklar}

1. Dörfer C, Benz C, Aida J, et al. The relationship of oral health with general health and NCDs: a brief review. Int Dent J. 2017;67(2):14-8

2. Segura-Egea JJ, Martín-González J, Castellanos-Cosano L. Endodontic medicine: connections between apical periodontitis and systemic diseases. Int Endod $\mathbf{J}$. 2015;48(10):933-51.

3. Teng YTA, Taylor GW, Scannapieco F, et al. Periodontal health and systemic disorders. J Can Dent Assoc. 2002;68(3):188-92.

4. Otomo-Corgel J, Pucher JJ, Rethman MP, et al. State of the Science: Chronic Periodontitis and Systemic Health. J Evid Based Dent Pract. 2012;12(3):20-8

5. Sopi M, Meqa K. Association of dental foci of infection and rosacea: a case report. Gen Dent. 2019;67(6):52-54

6. Mensch K, Nagy G, Nagy Á, et al. Characteristics, diagnosis and treatment of the most common bacterial diseases of the oral cavity. Orv Hetil. 2019;160(19):739-46.

7. Karunakaran JV, Abraham CS, Karthik AK, et al. Successful Nonsurgical Management of Periapical Lesions of Endodontic Origin: A Conservative Orthograde Approach. J Pharm Bioallied Sci. 2017;9(1):246-51.

8. Stamos A, Mills S, Malliaropoulos N, et al. The European Association for Sports Dentistry, Academy for Sports Dentistry, European College of Sports and Exercise Physicians consensus statement on sports dentistry integration in sports medicine. Dent Traumatol. 2020;36(6):680-4.

9. Gay-Escoda C, Vieira-Duarte-Pereira D-M, Ardèvol J, et al. Study of the effect of oral health on physical condition of professional soccer players of the Football Club Barcelona. Med Oral Patol Oral Cir Bucal. 2011;16 (3):436-9.

10. Gallagher J, Ashley P, Petrie A, et al. Oral health-related behaviours reported by elite and professional athletes. $\mathrm{Br}$ Dent J. 2019;227(4):276-80.

11. Fiorillo L, Musumeci G. TMJ Dysfunction and Systemic Correlation. J Funct Morphol Kinesiol. 2020;5(1):20.

12. Bryant S, McLaughlin K, Morgaine K, et al. Elite athletes and oral health. Int J Sports Med. 2011;32(9):720-4.

13. Sirimaharaj V, Messer LB, Morgan MV. Acidic diet and dental erosion among athletes. Aust Dent J. 2002;47(3):228 36.

14. Needleman I, Ashley P, Meehan L, et al. Poor oral health including active caries in $187 \mathrm{UK}$ professional male football players: clinical dental examination performed by dentists. Br J Sports Med. 2016;50(1):41-4

15. Patti A, Bianco A, Messina G, et al. The influence of the stomatognathic system on explosive strength: a pilot study. J Phys Ther Sci. 2016;28(1):72-5.

16. Needleman I, Ashley P, Petrie A, et al. Oral health and impact on performance of athletes participating in the London 2012 Olympic Games: a cross-sectional study. Br J Sports Med. 2013;47(16):1054-8

17. Moye ZD, Zeng L, Burne RA. Fueling the caries process: carbohydrate metabolism and gene regulation by Streptococcus mutans. J Oral Microbiol. 2014;5:6.

18. Dartevelle JL, Goupy L, Frey A. Dental Medicine. In: Krutsch W, Mayr HO, Musahl V, Della Villa F, Tscholl PM, Jones H, eds. Injury and Health Risk Management in Sports. A Guide to Decision Making. 2020; 287-289. Berlin, Germany: (C) ESSKA Heidelberger Platz, ISBN 978-3-66260751-0 ISBN 978-3-662-60752-7 (eBook).

19. Hamamcılar O, Akınoğlu B, Kocahan T, ve ark. Sporcularda Maksilla-Mandibuler Cene Posterior Bölge Dental Ekstraksiyonunun Quadriceps Kas Kuvveti Üzerine Etkisi. Turkiye Klin J Sports Sci. 2018;10(1):37-43.

20. Needleman I. Consensus statement: Oral health and elite sport performance. Br Dent J. 2014;217(10):587-90. 
21. Akınoğlu B, Kocahan T, Özsoy H, ve ark. Kadın ve Erkek Voleybol Sporcularında Diz Eklemi Kas Kuvveti ve Kas Kuvvet Dengesinin Karşılaştırılması. Turkiye Klin J Sports Sci. 2019;11(2):67-73

22. Hamamcilar O, Nefes A, Kocahan T, ve ark. Sporcularda Basit Şeker Tüketiminin Ağız ve Diș Sağlığına Etkisinin İncelenmesi. Turkiye Klin J Sports Sci. 2020;12(1):58-64.

23. Hamamcılar O, Akınoğlu B, Kocahan T, ve ark. Sporcularda Diş Çürügünün Quadriceps Kas Gücü ile İlişsisi. Turkiye Klin J Sports Sci. 2018;10(2):51-6.

24. Hamamcılar O, Kocahan T, Akınoğlu B, et al. Effect of dental caries and the consequential variation in blood parameters on the anaerobic performance of rowing athletes. Med J Islamic World Acad Sci. 2019;27(2):55-60.

25. Hamamcılar O, Kocahan T, Akınoğlu B, et al. Effect of poor oral health on respiratory functions and hence sportive performance. Med J Islamic World Acad Sci. 2018;26(3):74-79.
26. Baltzopoulos V, Brodie DA. Isokinetic dynamometry. Applications and limitations. Sports Med. 1989;8(2):10116.

27. Ismail PMS, Apoorva $\mathrm{K}$, Manasa $\mathrm{N}$, et al. Clinical, radiographic, and histological findings of chronic inflammatory periapical lesions-A clinical study. J Family Med Prim Care. 2020;9(1):235-8

28. Solleveld H, Goedhart A, Bossche LV. Associations between poor oral health and reinjuries in male elite soccer players: a cross-sectional self-report study. BMC Sports Sci Med Rehabil. 2015;7:11

29. Calvo AM, Brozoski DT, Giglio FPM, et al. Are antibiotics necessary after lower third molar removal? Oral Surg Oral Med Oral Pathol Oral Radiol. 2012;114(5):199-208.

30. Roubenoff R. Physical activity, inflammation, and muscle loss. Nutr Rev. 2007;65 (12 Pt 2):208-12 